\title{
Psychological Disturbances and Quality of Life in Obese and Infertile Women and Men
}

\author{
Piotr Kocełak, ${ }^{1}$ Jerzy Chudek, ${ }^{2}$ Beata Naworska, ${ }^{3}$ Monika Bạk-Sosnowska, ${ }^{4}$ \\ Barbara Kotlarz, ${ }^{3}$ Monika Mazurek, ${ }^{3}$ Pawel Madej, ${ }^{5}$ Violetta Skrzypulec-Plinta, ${ }^{6}$ \\ Piotr Skałba, ${ }^{5}$ and Magdalena Olszanecka-Glinianowicz ${ }^{1}$
}

\author{
${ }^{1}$ Health Promotion and Obesity Management Unit, Department of Pathophysiology, Medical University of Silesia, \\ 40-752 Katowice, Poland \\ ${ }^{2}$ Pathophysiology Unit, Department of Pathophysiology, Medical University of Silesia, 40-752 Katowice, Poland \\ ${ }^{3}$ Obstetric Propaedeutics Unit, Department of Woman's Health Care, Medical University of Silesia, 40-752 Katowice, Poland \\ ${ }^{4}$ Psychology Unit, Medical University of Silesia, 40-752 Katowice, Poland \\ ${ }^{5}$ Department of Endocrinological Gynecology, Medical University of Silesia, 40-752 Katowice, Poland \\ ${ }^{6}$ Department of Women's Health, Medical University of Silesia, 40-752 Katowice, Poland
}

Correspondence should be addressed to Piotr Kocełak, pkocelak@sum.edu.pl

Received 29 March 2012; Accepted 21 May 2012

Academic Editor: Renato Pasquali

Copyright () 2012 Piotr Kocełak et al. This is an open access article distributed under the Creative Commons Attribution License, which permits unrestricted use, distribution, and reproduction in any medium, provided the original work is properly cited.

\begin{abstract}
Anovulatory cycles and endometriosis are the main causes of female infertility. The most frequently anovulatory cycles are related to polycystic ovary syndrome (PCOS) commonly associated with obesity and hormonal disturbances in the course of obesity. Recently published studies revealed that infertility affects about one in six couples during their lifetime and is more frequent in obese. Obesity is also associated with male infertility related to erectile dysfunction, hormonal disturbances and lower semen quality. Any of these above mentioned disorder is the important risk factor of psychological disturbances and poor quality of life among women and men in the reproductive age. On the other hand the mood disorders may exacerbate the hormonal disturbances and worsen the effectiveness of infertility management. Infertility, its therapy with accompanying psychological disturbances may also significantly affect the partners relationships. The review summarize the results described in the current literature on the association between obesity and infertility and psychological disturbances as well as their impact on quality of life and sexual functioning in women and men. Moreover, the impact of infertility and psychological disturbances on partners relationships is discussed.
\end{abstract}

\section{Introduction}

The number of infertile subjects worldwide in 2005 year was estimated at 60-80 million with their annual growth on about 2 million. In developed countries infertility is diagnosed in $17-26 \%$ of reproductive age couples. The prevalence of infertility increases with age from $20 \%$ among subjects $35-$ 39 years old to $25-30 \%$ among those 40 years and over [1]. The percentage of female and male infertility causes is similar $(40 \%)$, and in $20 \%$ of couples both partners are affected [2].

Infertility is defined as inability to conceive a child by a couple in a stable relationship during the year of regular intercourse without the use of contraceptive methods.
The prevalence of obesity in Europe is estimated at 10$20 \%$ of men and $10-25 \%$ of women [3], while in the United States of America at $32.2 \%$ and $35.5 \%$ [4], respectively, with continuous tendency to grow. Thus in consequence the number of men and women diagnosed with infertility related to obesity is also increasing $[5,6]$.

Anovulatory cycles and endometriosis are the main causes of female infertility. The most frequent anovulatory cycles are related to polycystic ovary syndrome (PCOS) occurrence, commonly associated with obesity and hormonal disturbances in the course of obesity $[7,8]$. Recently published studies revealed that infertility affects about one in six couples during their lifetime and is more frequent in obese 
[9]. The prevalence of PCOS is estimated at $5-10 \%$ of women in childbearing age. Hormonal disturbances in PCOS include insulin resistance, hyperinsulinemia, inadequate gonadotropins secretion, and hyperandrogenism [10]. In the last decade the results of numerous studies revealed that hormones of adipose tissue (adipokines) play a role in the PCOS development $[11,12]$. Infiltration of adipose tissue with macrophages, disturbed adipokines secretion, increased lipogenesis, and free fatty acids release constitute the key elements in the pathogenesis of insulin resistance development $[13,14]$. Moreover, adipokines may participate in the PCOS development by other pathways. It has been suggested that changes of their secretion influence LH and FSH release as well as directly affect ovary steroidogenesis $[11,12,15,16]$, while PCOS-related hyperandrogenism manifests clinically by irregular menstruation, hirsutism, acne, and hair loss and frequently by infertility [17].

The risk factors of male infertility include age, some chronic diseases, especially obesity and its related disorders as well as infectious diseases, use of some medications, environmental factors (lead, arsenic, aniline dyes, ionizing radiation, electromagnetic fields, exposure), and lifestyle factors (high-fat and high-caloric diet, low physical activity, smoking, drinking and drug use, as well as tight and plastic clothing) $[5,6]$.

The relationship between obesity and infertility in men was first described by Avicenna in the 10th century. Current studies revealed that the risk of infertility increases with obesity grade [18] regardless of age and female partner's BMI and smoking habits of both partners [19]. It has also been shown that obese couples where both partners are affected are less fertile than those with normal body mass $[18,19]$.

It is well known that obesity is associated with erectile dysfunction. The risk factors of erectile dysfunction include obesity grade, visceral obesity, low testosterone level, and physical inactivity. The pathophysiological links between obesity and erectile dysfunction are poorly understood. It is suggested that the relationships include endothelial dysfunction, especially decreased endothelial nitric oxide synthase (eNOS) activity and NO release related to chronic, systemic microinflammation and insulin resistance as well as suppression of hypothalamic-pituitary-testicular axis. It has also been shown that decreased testosterone level in obese men increases the risk of vascular pathology occurrence. Thus, both testosterone deficiency and endothelial dysfunctions related to the other disturbances are factors causing the decreased eNOS expression and activity followed by penile vascular insufficiency. Currently, it is established that erectile dysfunction is the symptoms of endothelial injury. On the other hand, as it was mentioned above, testosterone deficiency is a risk factor of endothelial dysfunction and cardiovascular disease development [20,21]. Pasquali et al. [22] showed that weight loss improves androgen imbalance and erectile function.

Obesity-related hormonal disturbances are not restricted to androgen deficiency. It was suggested that decreased sex hormone-binding globulin (SHBG) and increased free testosterone levels in consequence favor testosterone to estradiol conversion in adipose tissue. Decreased testosterone-to-estradiol ratio contributes to impaired spermatogenesis and infertility development [23]. Regardless of the lower total testosterone level, its free fraction is decreased only by $5 \%$ in obese than in normal weight men due to markedly lower levels of circulating SHBG [24]. The decrease of SHBG synthesis is related to insulin resistance. It should be emphasized that hormonal disturbances worsen proportionally to the degree of obesity [25]. It has been shown that testosterone level in obese men is inversely proportionally related to circulating leptin concentration. Leptin directly inhibits testosterone synthesis by membrane receptors on testicular Leydig cells [26-28]. Additionally, decreased $\mathrm{LH}$ and inhibin B levels in obese young men were found $[29,30]$. Moreover, the results of experimental study revealed that inhibin B level is the marker of Sertoli cells number [31]. Thus decreased inhibin B level in obese men may be associated with fewer number of Sertoli cells and lower sperm count. It has also been suggested that decreased insulin-like factor 3 level in obese men is the result of a primary Leydig cells dysfunction and may be reliable marker of this cells general impairment [32]. The results of studies assessing the impact of obesity or visceral obesity on semen parameters are inconsistent. Some [23-35] but not all studies [36-38] revealed negative relation between BMI and sperm parameters.

Both obesity and infertility are the important risk factors of psychological disturbances and poor quality of life among women and men in reproductive age. On the other hand the mood disorders may exacerbate the hormonal disturbances and worsen the effectiveness of infertility management.

Female gender per se is the risk factor for mood disorders development. The prevalence of mood disorders, especially major depression and anxiety in general population, is higher by $50 \%$ among childbearing age women than in men [39-41]. The occurrence of mental illness is significantly increased among infertile subjects [42].

The paper summarizes the results described in the current literature on the association between obesity and infertility and psychological disturbances as well as their impact on quality of life and sexual functioning in women and men. Moreover, the impact of infertility and psychological disturbances on partners relationships is discussed.

\section{The Possible Links between Obesity and Depression}

Disturbances in serotonin release are the cause not only of mood decrease but also increase in consumption of carbohydrate-rich foods and aversion to physical activity [43]. Additionally, stress and depression symptoms are associated with increased hypothalamic-pituitary-adrenal (HPA) axis activity. In turn, its chronic overactivation and excessive cortisol level may be responsible for fat accumulation, especially of visceral localisation. It is suggested that brain reward circuitry plays the central role in the activation of stress-induced food intake. Furthermore, highly palatable food or activation of HPA axis releases opioids attenuating detrimental effect of stress response by inhibiting HPA axis. 
Moreover, elevated cortisol level increases food consumption by changes in action of mediators regulating hunger and satiety, such as neuropeptide Y (NPY), leptin, and insulin [44]. The results of a single study revealed that chronic microinflammation related to obesity may be a factor that participates in depression development [45]. However, our study did not confirm this link between obesity and depression [46]. The results of experimental studies have also suggested that gastrointestinal tract hormones, such as ghrelin and peptide YY (PYY), participate in mood disorders development. It was shown that in rats under chronic stress condition increased ghrelin levels defend against depressive symptoms [47]. The mechanism of ghrelin action on mood is associated with the suppression of cannabinoid-1 (CB1) and melanin-concentrating hormone- 1 receptors by this hormone $[48,49]$. In turn the results of clinical studies revealed that suppression of CB1 receptors by its antagonist had the increased potential for depression development in human [50]. On the other hand ghrelin increases the expression of NPY in hypothalamic neurons and NPY has antidepressant activity, in both rodents and human [51], while PYY inhibits the release of NPY [52]. In obese subjects decreased circulating levels of both ghrelin and PYY were shown $[53,54]$, and weight loss was increasing their levels $[55,56]$. However, we did not observe differences between plasma ghrelin and PYY levels in obese subjects with and without depression [57]. As shown above pathophysiological links between obesity and mood disorders are multifactorial and not fully clarified. The results of previously published studies indicated the mutual stimulation of both diseases in their development. Furthermore, changes in the activity of HPA axis related to depression may contribute to the occurrence of infertility, enhanced by the changes of hormonal adipose tissue activity in obesity.

\section{Mood Disorders in Obese and Infertile Women}

The epidemiological studies revealed higher prevalence of mood disorders, especially depression, in obese women ( $14 \%$ versus $10 \%$, resp.) but not in obese men, than in the general population [58-61]. Of interest obese men had lower risk of major depression [60].

It should be also emphasized that the prevalence and severity of depression symptoms among obese subjects referred both to a conservative and surgical treatment with a degree of obesity [62-65]. It is suggested that the overrepresentation of depressive subjects among obese women is associated with binge eating disorder [66].

Mood disorders in obese may by partially related to low self-esteem. Social discrimination of obese starting from childhood, assigning them negative features of character and self-awareness of lower attractivity, is more pronounced in women [67]. Thus women have lower self-esteem, which predisposes them to mood disorders development [68]. Morbid obesity is associated with the highest discrimination, comorbidity, and the lowest health-related quality of life, as well as the frequent tendency for food intake in response to negative emotions [69]. Recently an association between body mass and distress has also been found [70]. Other risk factors for depression symptoms development in obese are chronic bodily pain, disability, self-care, and work-related activities difficulties as well as stigmatization of obese subjects [71].

It has also been shown that lifetime diagnosis of depression and anxiety is associated with obesity [72]. The risk of depression development in obese American aged 50 years or over during 5-year followup was doubled [73].

On the other hand, it was shown that depression is also a risk factor of obesity development during 2-year followup [74]. Additionally, in adolescent girls depression was a predictor of obesity development, while obesity was the risk factor of depressive episodes number [75]. The factors favoring obesity development in depressive subject are lower physical activity and increased hunger related to the use of some psychotropic drugs [76]. Additionally, depression predicts visceral fat accumulation associated with higher activity of HPA axis and adrenal gland volume as well as corticosteroids levels [77-79]. The significant association between major and moderate depressive symptoms and waist circumference is independent from the coexistence of chronic diseases, including overweight and obesity [80,81].

Weight loss above $5 \%$ of the initial body mass improves mood, bodily satisfaction, self-esteem, and self-confidence as well as physical health [82-86]. It has also been shown that the occurrence of psychological disturbances, especially depression, anxiety, and binge eating does not predict the adherence and effectiveness of weight loss programs [87]. However, mood disorders may disturb the compliance to dietary and physical activity recommendations [88].

It is doubtful whether the weight reduction itself may significantly improve the course of severe depression [88]. Therefore obese with severe depression necessitate pharmacotherapy and psychotherapy before and during weight loss management $[89,90]$. There is the lack of studies assessing the impact of mood disturbances on weight maintenance as well as the weight regain consequences on mood disorders.

The prevalence of anxiety among obese subject is estimated at 37\%, and unlike depression, it is not associated with gender, education level, and treatment referral [91]. It seems that occurrence of anxiety is more persistent than depression symptoms. Anxiety seems to be a trigger for emotional eating as well as for bingeing. The results of numerous studies revealed an association between anxiety or emotional eating and obesity [92].

The associations between mental health in PCOS women and age, BMI, education level, physical activity and infertility were found [93]. Some authors showed that both negative body image and self-worth are important risk factors of depression and anxiety development in PCOS women as well as decreased QoL [94]. In PCOS women, obesity is the main risk factor for development of mental illness, anxiety, and social fear [95]. A higher prevalence and severity of depression has been reported in PCOS women $[96,97]$. It is related to obesity, emotional disturbances, hirsutism, acne, menstrual predictability, and infertility [96]. Obesity interferes with self-perception and decreased self-esteem as 
well as impairs sexual functioning. Infertility may be a cause of misunderstandings and tension in the family and generate problems in the workplace, especially in women who had never given birth $[98,99]$. Adolescent girls diagnosed with PCOS report obesity as most distressing symptom of the disease. Additionally, the relationship between self-perception and depression level was shown [100]. The disturbed selfperception in adolescent PCOS is an often cause of extreme exercise application for weight control and eating disorders development [101]. Moreover, in these girls self-esteem is also decreased by acne and hirsutism [102], while the adult PCOS women have less feminine self-perception due to infertility, hirsutism, and menstrual problems [103]. The association between hirsutism degree and anxiety, psychotic symptoms sadness and frustration was found [94, 104]. Of interest the results of a single study showed beneficial effect of higher free testosterone level on mood [105]. However, other studies did not reveal the association between depression and testosterone level [96]. The associations between depressive disorders or social phobias and BMI as well as free androgen index (FAI) values in PCOS women were also found [106]. It was also suggested that the elevated LH and androgens levels which alter the monoamine balance are the link between mood disorders and PCOS [107], while some authors claim a positive relationship between depressive symptoms and HOMA-IR values but not irregular menses, hirsutism, hair loss, or acne [95].

In PCOS group frequent suicide attempts as well as anxiolytic and antidepressant drugs use were reported [101]. On the other hand depression occurrence may exacerbate the hormonal disturbances in PCOS women, while its treatment may ameliorate these symptoms $[96,107]$. The lower prevalence of depression was found among PCOS women receiving oral contraception [95]. It is interesting observation because oral contraception given for contraceptive purposes increases frequency of depression incidence itself [108].

As it was mentioned above hormonal disturbances occurring in obese and PCOS women are common causes of infertility, and both these conditions are associated with higher prevalence of depression symptoms. Additionally, infertility increases the risk of mood disorders development.

Numerous studies showed that more than $50 \%$ of couples consider infertility as the most disappointing experience in their life [109]. Even $80 \%$ thought about infertility as stressful or very stressful experience [110] or as feeling of grievance, depression, sin, threat, marital problems, and disappointment [111]. On the basis of the results obtained by self-reported Beck Depression Inventory (BDI) the depression symptoms were shown in $37 \%$ of infertile women; among them $19.4 \%$ have moderate or severe depression symptoms [112, 113]. Many factors such as causes and length of infertility and the therapeutic strategies may influence psychological disturbances in infertile couples in a different way among men and women [114]. It is suggested that depression development in infertile women is the result of prolonged and severe normal psychological response to the diagnosis which is the grief and mourning [115]. It has also been found that the frequency of depression in infertile women increases with the duration of therapy [116].
Higher frequency of mood disorders (anxiety and depression) was shown in infertile women undergoing in vitro fertilization (IVF), especially during embryo transfer or egg retrieval [114]. Before initiation of infertility treatment, depression was diagnosed in 33\% of women and 3.5\% of men, and its prevalence increased after IVF failure to $43 \%$ and $8 \%$, respectively $[117,118]$. At the same time, the frequency of anxiety increased from $10.6 \%$ before to $14.2 \%$ after IVF in women [118]. Women are more prone to be affected by stress, anxiety, and discouragement and are more engaged into the diagnostic and therapeutic procedures [45]. Moreover, the risk factors of mood disorders in infertile women are time of applying for pregnancy, younger age, and partner with anxiety symptoms. In contrast, the risk factors of mood disorders in infertile men or partners of infertile women include temporary job, the first visit of IVF treatment, and an anxious partner [119]. However, the results of another study did not confirm the influence of diagnosis, age of female, duration of infertility, number of IVF procedures on mood disorders in infertile women and revealed that mood disorders are affected by personality and stress coping strategies [20]. The absence of support from husband and social discrimination are among the important risk factors of mood disorders development and main stressors disturbing $\mathrm{GnRH}$ pulsatility resulting in anovulatory cycles in infertile women [120]. It should be emphasized that psychological distress during fertilization and pregnancy may increase the rate of complications in the newborn at the time of and after delivery. Mothers conceived by IVF are more worried about survival and normality of their unborn babies, about damage to their babies during childbirth, and about separating from their babies after birth [121].

Depressive symptoms are associated with menstrual abnormalities, such as rare menarche, irregular cycles, and secondary amenorrhea [122]. The relationship between menstrual cycle disturbances and mood disorders seems to be reciprocal. The prevalence of depressive symptoms in women with functional hypothalamic amenorrhea (FHA) is similar to that observed in women with organic menstrual abnormalities [123]. The lower rates of fertility have been reported in women with a history of major depression episodes [124]. However, one study restricts the lower rate of fertility only to depressive women with suicidal attempts [125].

The impaired fertility in depressive women may be also related to the use of antidepressants responsible for the higher risk of spontaneous abortion, hyperprolactinemia, hyperandrogenism, hyperinsulinemia, and menstrual disturbances [126].

The explanation of the association between mental illness and infertility is difficult. It is caused by the different definitions of infertility, length of marriage attempts to conceive and infertility treatment timing of the diagnosis (before or after the onset of psychiatric episode), age, as well as other causes of decreased fertility such as male infertility, cultural factors and availability of assisted conception [127-129].

It was revealed that development of somatization, depression, anxiety, and paranoid ideation is associated with actual 
treatment for infertility and feelings of loneliness as well as sexual and financial factors [130].

Psychotherapy of infertile couples decreases anxiety and depression resulting in improvement of HPA axis function and increases the likelihood of conception $[129,130]$. It has also been shown that isolated psychological interventions increase the rate of pregnancy [131]. Successful conception is reported to be lower in women with the history of infertility if followed by a high rate of major depression $(69.2 \%$ versus $30 \%)$, anxiety $(23.1 \%$ versus $3 \%)$, panic disorders $(15.4 \%$ versus $0 \%)$, phobia $(23.1 \%$ versus $10 \%)$, and bulimia $(7.7 \%$ versus $0 \%$ ) during pregnancy [132]. Thus, the results of this study necessitate psychological care in this group of pregnant women.

\section{Other Psychological Disturbances and Mental Illness in Obese and Infertile Women}

The higher prevalence of distress, interpersonal sensitivity, and obsessive-compulsive symptoms has been shown in PCOS women $[133,134]$, while similar anger and aggression levels in PCOS and non-PCOS women were found [94]. Additionally, body dissatisfaction related to hirsutism and negative body image self-perception are more frequent among PCOS women $[94,133]$. Body dissatisfaction in adolescents may be a risk factor of eating disorders and depression development [135]. However, the results of studies that assessed the prevalence of eating disorders in PCOS women are inconsistent. Some studies [136], but not all [137], revealed higher frequency of bulimia in PCOS women. On the other hand, it is suggested that bulimia is the risk factor of PCOS development as overeating and starving episodes impair insulin sensitivity and are associated with ovarian morphology changes [136].

Mental illness is more frequently diagnosed in infertile women than men $(61.1 \%$ versus $21 \%)$. The most prevalent disturbances among infertile subjects are mood disorders $(59.6 \%)$, especially anxiety (67\% infertile women). Dysthymia, somatization, and conversion disorders were observed in infertile women only. The risk factors of psychiatric morbidity among infertile subjects include female gender, the quality of the couple's relationship, type and length of infertility as well as diagnostic procedures, number of treatment cycles, and outcome of IVF $[45,138]$. A great need for conceiving a child among PCOS than non-PCOS women ( $42 \%$ versus $6 \%$ ) is considered as the important risk factor of psychological and emotional disturbances [134].

The higher depression, psychoticism, and somatization levels and worse interpersonal relations were found among infertile than fertile women [21], while, the results of other studies revealed higher prevalence of paranoid ideation and lower psychoticism and phobic anxiety in infertile women [129]. Additionally, dominance of somatization and anxiety and lower occurrence of psychoticism and panic phobia among these subjects have also been shown [139].

The higher prevalence of alexithymia in infertile women was found. Alexithymia seems to be the psychological response and the strategy of coping as well as adaptation to the diagnosis and the infertility management [140]. It is also considered as the form of depression [141].

\section{Quality of Life (QoL) in Obese and Infertile Women}

Obesity decreases both physical and mental aspects of quality of life, especially in women [142]. Health-related quality of life (HRQoL) decreases proportionally to increased BMI and fluctuations in body weight, coexisting comorbidities including mental illness and binge eating. The physical aspect of HRQoL is deteriorated especially by the coexistence of mood disorders, obesity, and its comorbidities [31]. Among subjects aged 60 years or more, obesity is associated with worse physical functioning regardless of age, especially in women [143]. Among elderly population higher waist circumference is related to lower HRQoL but higher occurrence of depressive symptoms only in women [144]. Surprisingly, higher HRQoL in obese men was found [145]. Additionally, it is shown that physical domain of HRQoL diminishes, while self-esteem and public distress improve with age [144]. Obesity decreases self-esteem and increases body dissatisfaction especially in adolescents and young women. Low self-esteem particularly coexisting with anxiety is the reason of social isolation among obese subjects [146]. Elevated BMI and waist circumference values are independent risk factors of urogenital dysfunction, especially urinary incontinence which is the reason for decreasing mostly emotional aspect of HRQoL and increasing feeling of frustration but not affect sexual lust $[147,148]$. It should be emphasized that BMI affects the HRQoL independently of questionnaire used to its assessment [149]. In morbid obese significant improvement of HRQoL, both physical and psychological aspects as well as self-esteem, social life, sexual activity, and disposition for physical activities or work, after surgical treatment of obesity with large weight loss were obtained [150-152]. Regardless of the observed improvement in HRQoL and disease-specific quality of life (DSQoL) one-year after procedure and their maintenance during 5-year followup the HRQoL values are lower than in age- and gender-matched general population [153].

All physical, psychological, and emotional aspects of HRQoL are decreased [136] and strongly associated with overweight/obesity and hirsutism grade in PCOS women [97]. It was found that in PCOS women weight loss obtained by pharmacotherapy decrease in hirsutism severity improves mostly psychological domain of HRQoL [154]. Additionally, infertility seems to be important factor that alters psychological aspect of HRQoL in PCOS women [155]; however duration and the cause of infertility seem not to influence HRQoL [156]. Among couples undergoing IVF procedure higher HRQoL was shown in males than in females [157]. However, some previously published studies did not confirm the difference in mental health between infertile and fertile PCOS women [158]. Of interest, higher depression level and lower body satisfaction were found in infertile PCOS than in women infertile due to other causes [133]. Ethnic origin is an important confounder in QoL comparison however in 
both Caucasian and South Asian PCOS HRQoL was similar and significantly lower than in non-PCOS women. In both ethnic groups obesity and infertility were important factors deteriorating HRQoL, while menstrual disturbances were affecting only Asian PCOS women [159].

It should be emphasized that physical dimension of HRQoL in PCOS women is similar to that observed in patients diagnosed with asthma, epilepsy, diabetes, and back pain, while the mental health is about $20 \%$ worse in PCOS [160].

\section{Sexual Dysfunction and Sexual Aspect of Quality of Life in Obese and Infertile Women}

Obesity is associated with fewer sexual partners in both men and women and having a partner at all by women. However, frequency of sexual intercourses and sexual practices is similar in obese and normal weight subjects [161]. Both abortion and unintended pregnancies due to the use of less effective contraceptive methods are more frequently reported in obese women [162].

Obese men have higher tendency to choose nonobese partners than obese women. Stronger social pressure to have a partner for a woman than for a man seems to be the explanation [163].

Some studies revealed that obesity is not associated with sexual dissatisfaction or with experience of sexual abuse. However, it was shown that sexual abuse influences eating behavior and may be the cause for both obesity and anorexia nervosa development [143].

Sexual dysfunction related to obesity was observed in both perimenopausal and postmenopausal obese women with lower HRQoL. It decreased appearance and sexuality self-perception [160]. However, the results of studies assessing the impact of obesity on female sexual dysfunction including arousal, lubrication, orgasm, and satisfaction are inconsistent $[164,165]$. Obese subjects frequently report sexual disturbances such as lack of enjoyment of sexual activity, difficulties with sexual performance, lack of sexual desire, and avoidance of sexual encounters. Sexual QoL is mostly impaired in morbid obese women seeking bariatric surgery [166].

An association between worse HRQoL and decreased sexual relationship within marriage, proportionally to hirsutism severity, was reported [167]. It was also shown that HRQoL in PCOS women is affected by emotional problems, pain, energy/fatigue, emotional well-being, and social functioning but not BMI [135]. Nevertheless, the results of other studies showed that obesity is the main factor affecting sexual dissatisfaction and QoL [160]. However, no association between sexual functioning and obesity or infertility as well as androgen levels was found [168].

In PCOS women lower total QoL and sexual satisfaction frequently coexist with anxiety, depressive and obsessivecompulsive disorders [135]. Additionally, worse sexual function is associated with higher androgens and LH levels in PCOS [169]. It has also been found that PCOS women experience less sexual attractiveness and sexual desire [170].
Contrary, the rate of having a sexual partner, the frequency of sexual intercourse or sexual thoughts and fantasies are similar both in PCOS and non-PCOS women. The reason for lower sexual satisfaction may be the imaging that partner felt less satisfied with their sexual life and that he found her as less sexually attractive [136]. Among the factors that influence self-esteem are also obesity, acne, hirsutism, infertility, and psychological distress $[135,170,171]$.

\section{Psychological Disturbances Related to Obesity and Infertility in Men}

Only few studies described an association between emotional state and infertility in men. It was shown that acute stress associated, for example, with earthquake and war affects male fertility, not only in the aspect of erectile function but also the quantity and quality of semen $[172,173]$. Moreover, the negative effect on semen quality of less traumatic events such as exams has also been found [174]. Additionally, temporary decrease of men fertility related to chronic stress after death of relative was described [175]. It was shown that during stress superoxide dismutase activity increases significantly while catalase activities remain unchanged. Moreover, spermatozoa concentration, motility index, and percentage of rapid progressive motility decrease under stress [176].

It was shown that the reference of a couple to infertility management clinic due to his partner's infertility is related to severe negative emotions in men. Moreover, it was suggested that emotional stress is the frequent risk factor of therapy discontinuation $[176,177]$.

The above-mentioned negative emotions may be the cause of erectile and ejaculation dysfunction as well as decreased libido and number of relations [178]. On the other hand male reason of infertility may be the cause of guilt or sadness and in turn depression development [179181]. However, as it was mentioned above the main risk factors associated with development of depression related to infertility are female gender [182]. The occurrence of depression or anxiety symptoms and lower testosterone level impairs spermatogenesis and decreases their sperm concentration [178, 183]. However, another study revealed that sperm count is not associated with anxiety and depression levels, but sperm motility is weakly and inversely related to depression level [184].

The prevalence of depression among infertile men is estimated at $5-15 \%$ and is significantly lower than among women $[175,180,182]$ and higher in Middle East region than in Western countries $[118,185]$.

In some countries, especially in Middle East region fatherhood is traditionally sociocultural determinant of masculinity. However, not only in these societies the stigma of infertility in men may be a cause of low self-esteem, considering themselves as second-class men, and reduced sense of masculinity [186].

High scores on neuroticism-related personality traits are risk factors of depression and anxiety disorders development in both infertile male and female. Additionally, high neuroticism scores are negatively associated with live birth [187]. 
The links between obesity, mood disorders, and infertility in men are poorly understood. Some studies revealed that obese men had lower frequency of depression symptoms [188]. The depression may be a cause of obesity development in men as negative emotions are frequently compensated by compulsive overeating. For example sweets increase serotonin release in brain and decrease tension, give a feeling of pleasure, and improve well-being [189-191]. In men the lack of sense of overeating but not the lack of body size is the cause of decreased mood and life satisfaction [192]. Thus, as was described above depression may be the cause of decreased fertility per se and indirectly by stimulation of obesity development. On the other hand in some cases male infertility may be the cause of depression and obesity development. In turn obesity may be the cause of infertility and subsequently development of depression. It should be emphasized that erectile dysfunction related to obesity may be the important risk factor of depression and anxiety development in men. It was found that male diagnosed with new onset erectile dysfunction also reported both depression and anxiety [193]. Moreover, Conrad et al. [194] revealed that some men may experience sexual dysfunction of a psychogenic nature in response to the diagnosis of infertility. It was also suggested that alexithymia and somatization are consequences of coping with male infertility [195]. Alexithymia in infertile men may play a defensive role as far as depression is concerned but increases the possibility of somatic complaints [196]. Regardless which of these disorders is the cause and which is the effect, their coexistence should be considered, and psychotherapy should be important element of this diseases management.

It should be mentioned that a frequent side effect of both typical, but also of many atypical antipsychotics such as amisulpride, risperidone, or ziprasidone used in some mental illness, is hyperprolactinaemia and in turn hypogonadism in both male and female [197]. The interesting observation is that male offspring of patients with schizophrenia had $12 \%$ fewer offspring [198].

\section{Quality of Life and Its Sexual Aspect in Obese and Infertile Men}

The lower HRQoL in physical domain and social functioning was reported in overweight adolescents. While in obese adolescents, additionally, emotional functioning was decreased. It should be emphasized that excess weight worsened HRQoL in the greater extent in girls than in boys [199]. Similar results were obtained in morbid obese subjects. Women had significantly lower HRQoL level than men, although they were younger, less obese, and less likely to be married. Both in men and in women increasing number of comorbidities was decreasing physical and mental HRQoL [189]. It has also been shown that mental HRQoL was affected by the presence of depression and eating behavior disorders but not by physical comorbidities and obesity grade. However only in men low physical self-perceived well-being was associated with obesity grade [200]. The most important predictor of physical and mental HRQoL components in morbid obese subjects was employment regardless of gender [201, 202]. Among other factors that deteriorated HRQoL in obese of both genders was depression [202]. Subthreshold depression and anxiety were the major predictors of QoL level in infertile men [203]. Isolated male infertility was associated with lower sexual, personal, and social strains QoL in men [204].

\section{Partners Relationships}

The studies assessing the QoL, sexual quality of life, and partnerships in infertile couples revealed interesting results. Shindel et al. [205] show significant discrepancies between partners only in psychological and social relationships domains. Depression in males affected all QoL domains, while in female only overall, psychological and physical. Additionally, in infertile couples male partner sexual function was related to female partner sexual function. The important predictors of men's relationship status in self-assessment were relationship duration and female partner assessment of relationships [206]. Moreover, Elia et al. [207] observed that in infertile couples women had poor marital adjustment QoL. The forced timing of intercourse around the woman's ovulatory cycle is associated with psychological pressure to try to conceive, and men may experience less intercourse satisfaction. Some authors observed that stressful situation related to the diagnosis of subfertility can reduce the pleasure of sex, independently from the severity of the semen alterations awareness [208]. On the other hand it was shown that successfully assisted reproduction technique does not constitute a risk for marital adjustment. Moreover, the shared stress of infertility may even stabilize marital relationships [209]. Additionally, it was found that diagnosis of male factor and infertility duration of 3-6 years were associated with the highest relationship instability and the lowest sexual satisfaction both in infertile females and males [210]. Sand et al. [211] revealed that in infertile couples most common problems are psychosexual disorders, including dyspareunia decreased libido and orgasmic failure in women, and premature ejaculations followed by erectile dysfunction, decreased libido and orgasmic failure in men. Psychosexual dysfunction and infertility were found to occur, in a large number of couples, together in association. These authors suggested that the most common cause for this problem is ignorance and lack of sex education.

Interesting findings were obtained in multinational Men's Attitudes to Life Events and Sexuality (MALES) study. The important determinants of self-perceived masculinity were being seen as honorable, self-reliant, and respected by friends, while factors stereotypically associated with masculinity, such as being physically attractive, sexually active, and successful with women, were deemed to be less important. Moreover, men deemed of significant importance for QoL factors such as good health, harmonious family life, and a good relationship with their wife/partner, while factors such as having a good job, having a nice home, living life to the full, or having a satisfying sex life were far less important. It should be emphasized that these determinants of selfperceived masculinity and QoL were similar in men with or without erectile dysfunction [212]. On the other hand 
it was also shown that network positions that afford independence and control over social resources are consistent with traditional masculine roles and may therefore affect men's sexual performance. When heterosexual man's female partner has more frequent contact with his confidants than he does-partner betweenness-his relational autonomy, privacy, and control are constrained; men are more likely to report erectile dysfunction [212]. These data suggest that psychological factors and partner relationships are important factors formative of a total and sexual QoL.

In summary, the reviewed data confirm the adverse impact of both obesity and impaired fertility on psychological disturbances and QoL especially in women. Mood disorders exacerbate hormonal disturbances, resulting in anovulatory menstrual cycles and decreased conception. In men mood disorders also decrease fertility by exacerbating erectile dysfunction and decrease semen quality. Mood disorders in both female and male are a risk factor of eating disorders and obesity development. Infertility and mood disorders affect the partners' relationships. Therefore the psychotherapy should be included in the management of both obesity and infertility. Such an approach will improve the effectiveness of infertility therapy and prevent development or worsening mood disorders in obese infertile women and men.

\section{References}

[1] G. R. Dohle, G. M. Colpi, T. B. Hargreave, G. K. Papp, A. Jungwirth, and W. Weidner, "EAU guidelines on male infertility," European Urology, vol. 48, no. 5, pp. 703-711, 2005.

[2] G. R. Dohle, A. Jungwirth, Z. Kopa, A. Giwercman, T. Diemer, and T. B. Hargreave, "Guidelines on male infertility 2009," in European Association of Urology Guidelines, pp. 164.

[3] World Health Organization, "Obesity and overweight," Fact Sheet N8311, World Health Organization, Geneva, Switzerland, 2006.

[4] K. M. Flegal, M. D. Carroll, C. L. Ogden, and L. R. Curtin, "Prevalence and trends in obesity among US adults, 19992008," Journal of the American Medical Association, vol. 303, no. 3, pp. 235-241, 2010.

[5] World Health Organization, International Statistical Classification of Diseases and Related Health Problems, 10th Revision, http://www.who.int/classifications/icd, 2007.

[6] C. Gnoth, E. Godehardt, P. Frank-Herrmann, K. Friol, J. Tigges, and G. Freundl, "Definition and prevalence of subfertility and infertility," Human Reproduction, vol. 20, no. 5, pp. 1144-1147, 2005.

[7] M. Olszanecka-Glinianowicz, M. Banaś, B. Zahorska-Markiewicz, D. Kuglin, J. Mokrzycka, and A. Mentel, "Determination of hormonal profile in obese women without additional disease and obese women with polycystic ovary syndrome," Endokrynologia Polska, vol. 55, no. 6, pp. 48-55, 2004.

[8] S. A. R. Doi, M. Al-Zaid, P. A. Towers, C. J. Scott, and K. A. S. Al-Shoumer, "Irregular cycles and steroid hormones in polycystic ovary syndrome," Human Reproduction, vol. 20, no. 9, pp. 2402-2409, 2005.

[9] R. M. Groves, W. D. Mosher, J. M. Lepkowski, and N. G. Kirgis, "Planning and development of the continuous national survey of family growth," Vital and health statistics. Series 1, no. 48, pp. 1-64, 2009.

[10] S. Franks, "Medical progress: polycystic ovary syndrome," The New England Journal of Medicine, vol. 333, no. 13, pp. 853-861, 1995.

[11] J. Villa and R. E. Pratley, "Adipose tissue dysfunction in polycystic ovary syndrome," Current Diabetes Reports, vol. 11, no. 3, pp. 179-184, 2011.

[12] C. Tersigni, F. Di Nicuolo, S. D’Ippolito, M. Veglia, M. Castellucci, and N. Di Simone, "Adipokines: new emerging roles in fertility and reproduction," Obstetrical and Gynecological Survey, vol. 66, no. 1, pp. 47-63, 2011.

[13] F. L. Torres-Leal, M. H. Fonseca-Alaniz, M. M. Rogero, and J. Tirapegui, "The role of inflamed adipose tissue in the insulin resistance," Cell Biochemistry and Function, vol. 28, no. 8, pp. 623-631, 2010.

[14] M. Olszanecka-Glinianowicz and B. Zahorska-Markiewicz, "Obesity as inflammatory disease," Postępy Higieny i Medycyny Doświadczalnej, vol. 62, pp. 249-257, 2008.

[15] M. Olszanecka-Glinianowicz, D. Kuglin, A. Dạbkowska-Huć, and P. Skałba, "Serum adiponectin and resistin in relation to insulin resistance and markers of hyperandrogenism in lean and obese women with polycystic ovary syndrome," European Journal of Obstetrics Gynecology and Reproductive Biology, vol. 154, no. 1, pp. 51-56, 2011.

[16] M. Olszanecka-Glinianowicz, P. Madej, D. Zdun et al., "Are plasma levels of visfatin and retinol-binding protein 4 (RBP4) associated with body mass, metabolic and hormonal disturbances in women with polycystic ovary syndrome?" European Journal of Obstetrics Gynecology and Reproductive Biology, vol. 162, no. 1, pp. 55-61, 2012.

[17] S. A. Arslanian, V. D. Lewy, and K. Danadian, "Glucose intolerance in obese adolescents with polycystic ovary syndrome: roles of insulin resistance and $\beta$-cell dysfunction and risk of cardiovascular disease," Journal of Clinical Endocrinology and Metabolism, vol. 86, no. 1, pp. 66-71, 2001.

[18] M. Sallmén, D. P. Sandler, J. A. Hoppin, A. Blair, and D. D. Baird, "Reduced fertility among overweight and obese men," Epidemiology, vol. 17, no. 5, pp. 520-523, 2006.

[19] R. H. N. Nguyen, A. J. Wilcox, R. Skjærven, and D. D. Baird, "Men's body mass index and infertility," Human Reproduction, vol. 22, no. 9, pp. 2488-2493, 2007.

[20] A. M. Traish, R. J. Feeley, and A. Guay, "Mechanisms of obesity and related pathologies:aAndrogen deficiency and endothelial dysfunction may be the link between obesity and erectile dysfunction," FEBS Journal, vol. 276, no. 20, pp. 5755-5767, 2009.

[21] A. A. Yassin, F. Akhras, A. I. El-Sakka, and F. Saad, "Cardiovascular diseases and erectile dysfunction: the two faces of the coin of androgen deficiency," Andrologia, vol. 43, no. 1, pp. 1-8, 2011.

[22] R. Pasquali, L. Patton, and A. Gambineri, "Obesity and infertility," Current Opinion in Endocrinology, Diabetes and Obesity, vol. 14, no. 6, pp. 482-487, 2007.

[23] A. O. Hammoud, N. Wilde, M. Gibson, A. Parks, D. T. Carrell, and A. W. Meikle, "Male obesity and alteration in sperm parameters," Fertility and Sterility, vol. 90, no. 6, pp. 2222-2225, 2008.

[24] N. E. Allen, P. N. Appleby, G. K. Davey, and T. J. Key, "Lifestyle and nutritional determinants of bioavailable androgens and related hormones in British men," Cancer Causes and Control, vol. 13, no. 4, pp. 353-363, 2002.

[25] H. K. Kley, T. Deselaers, and H. Peerenboom, "Evidence for hypogonadism in massively obese males due to decreased free 
testosterone," Hormone and Metabolic Research, vol. 13, no. 11, pp. 639-641, 1981.

[26] M. Caprio, A. M. Isidori, A. R. Carta, C. Moretti, M. L. Dufau, and A. Fabbri, "Expression of functional leptin receptors in rodent Leydig cells," Endocrinology, vol. 140, no. 11, pp. 4939-4947, 1999.

[27] A. M. Isidori, M. Caprio, F. Strollo et al., "Leptin and androgens in male obesity: evidence for leptin contribution to reduced androgen levels," Journal of Clinical Endocrinology and Metabolism, vol. 84, no. 10, pp. 3673-3680, 1999.

[28] T. Ishikawa, H. Fujioka, T. Ishimura, A. Takenaka, and M. Fujisawa, "Expression of leptin and leptin receptor in the testis of fertile and infertile patients," Andrologia, vol. 39, no. 1, pp. 22-27, 2007.

[29] S. J. Winters, C. Wang, E. Abdelrahaman, V. Hadeed, M. A. Dyky, and A. Brufsky, "Inhibin-B levels in healthy young adult men and prepubertal boys: is obesity the cause for the contemporary decline in sperm count because of fewer sertoli cells?" Journal of Andrology, vol. 27, no. 4, pp. 560-564, 2006.

[30] A. S. Aggerholm, A. M. Thulstrup, G. Toft, C. H. RamlauHansen, and J. P. Bonde, "Is overweight a risk factor for reduced semen quality and altered serum sex hormone profile?" Fertility and Sterility, vol. 90, no. 3, pp. 619-626, 2008.

[31] S. Ramaswamy, G. R. Marshall, A. S. McNeilly, and T. M. Plant, "Evidence that in a physiological setting Sertoli cell number is the major determinant of circulating concentrations of inhibin B in the adult male rhesus monkey (Macaca mulatta)," Journal of Andrology, vol. 20, no. 3, pp. 430-434, 1999.

[32] C. Foresta, A. Di Mambro, C. Pagano, A. Garolla, R. Vettor, and A. Ferlin, "Insulin-like factor 3 as a marker of testicular function in obese men," Clinical Endocrinology, vol. 71, no. 5, pp. 722-726, 2009.

[33] E. V. Magnusdottir, T. Thorsteinsson, S. Thorsteinsdottir, M. Heimisdottir, and K. Olafsdottir, "Persistent organochlorines, sedentary occupation, obesity and human male subfertility," Human Reproduction, vol. 20, no. 1, pp. 208-215, 2005.

[34] I. Fejes, S. Koloszár, J. Szöllosi, Z. Závaczki, and A. Pál, "Is semen quality affected by male body fat distribution?" Andrologia, vol. 37, no. 5, pp. 155-159, 2005.

[35] C. C. Wegner, A. L. Clifford, P. M. Jilbert, M. A. Henry, and W. L. Gentry, "Abnormally high body mass index and tobacco use are associated with poor sperm quality as revealed by reduced sperm binding to hyaluronan-coated slides," Fertility and Sterility, vol. 93, no. 1, pp. 332-334, 2010.

[36] T. K. Jensen, A. M. Andersson, N. Jørgensen et al., "Body mass index in relation to semen quality and reproductive hormones among 1,558 Danish men," Fertility and Sterility, vol. 82, no. 4, pp. 863-870, 2004.

[37] E. R. M. Hofny, M. E. Ali, H. Z. Abdel-Hafez et al., "Semen parameters and hormonal profile in obese fertile and infertile males," Fertility and Sterility, vol. 94, no. 2, pp. 581-584, 2010.

[38] T. M. Stewart, D. Y. Liu, C. Garrett, N. Jørgensen, E. H. Brown, and H. W. G. Baker, "Associations between andrological measures, hormones and semen quality in fertile Australian men: inverse relationship between obesity and sperm output," Human Reproduction, vol. 24, no. 7, pp. 1561-1568, 2009.

[39] M. M. Weissman and M. Olfson, "Depression in women: implications for health care research," Science, vol. 269, no. 5225, pp. 799-801, 1995.
[40] R. C. Kessler, H. Birnbaum, O. Demler et al., "The prevalence and correlates of nonaffective psychosis in the National Comorbidity Survey Replication (NCS-R)," Biological Psychiatry, vol. 58, no. 8, pp. 668-676, 2005.

[41] H. Volgsten, A. Svanberg, L. Ekselius, O. Lundkvist, and I. Sundstrom Poromaa, "Prevalence of psychiatric disorders in infertile women and men undergoing in vitro fertilization treatment," Human Reproduction, vol. 23, no. 9, pp. 20562063, 2008.

[42] D. Guerra, A. Llobera, A. Veiga, and P. N. Barri, "Psychiatric morbidity in couples attending a fertility service," Human Reproduction, vol. 13, no. 6, pp. 1733-1736, 1998.

[43] J. J. Wurtman, "Depression and weight gain: the serotonin connection," Journal of Affective Disorders, vol. 29, no. 2-3, pp. 183-192, 1993.

[44] T. C. Adam and E. S. Epel, "Stress, eating and the reward system," Physiology and Behavior, vol. 91, no. 4, pp. 449-458, 2007.

[45] Y. K. Kim, K. S. Na, K. H. Shin, H. Y. Jung, S. H. Choi, and J. B. Kim, "Cytokine imbalance in the pathophysiology of major depressive disorder," Progress in Neuro-Psychopharmacology and Biological Psychiatry, vol. 31, no. 5, pp. 1044-1053, 2007.

[46] M. Olszanecka-Glinianowicz, B. Zahorska-Markiewicz, P. Koceak et al., "Is chronic inflammation a possible cause of obesity-related depression?" Mediators of Inflammation, vol. 2009, Article ID 439107, 2009.

[47] M. Lutter, I. Sakata, S. Osborne-Lawrence et al., "The orexigenic hormone ghrelin defends against depressive symptoms of chronic stress," Nature Neuroscience, vol. 11, no. 7, pp. 752-753, 2008.

[48] M. Kanehisa, J. Akiyoshi, T. Kitaichi et al., "Administration of antisense DNA for ghrelin causes an antidepressant and anxiolytic response in rats," Progress in NeuroPsychopharmacology and Biological Psychiatry, vol. 30, no. 8, pp. 1403-1407, 2006.

[49] G. Burdyga, A. Varro, R. Dimaline, D. G. Thompson, and G. J. Dockray, "Ghrelin receptors in rat and human nodose ganglia: putative role in regulating $\mathrm{CB}-1$ and $\mathrm{MCH}$ receptor abundance," American Journal of Physiology, vol. 290, no. 6, pp. G1289-G1297, 2006.

[50] J. Proietto, I. Gantz, and R. D.. Carr, "A two-year study to assess the efficacy, safety, and tolerability of Teranabant in obese patients: 52 week results," International Journal of Obesity, vol. 32, Supplement 1, article 22, 2008.

[51] K. Eaton, F. R. Sallee, and R. Sah, "Relevance of neuropeptide Y (NPY) in psychiatry," Current Topics in Medicinal Chemistry, vol. 7, no. 17, pp. 1645-1659, 2007.

[52] K. Wynne, S. Stanley, and S. Bloom, “The gut and regulation of body weight," Journal of Clinical Endocrinology and Metabolism, vol. 89, no. 6, pp. 2576-2582, 2004.

[53] M. Tschöp, C. Weyer, P. A. Tataranni, V. Devanarayan, E. Ravussin, and M. L. Heiman, "Circulating ghrelin levels are decreased in human obesity," Diabetes, vol. 50, no. 4, pp. 707709, 2001.

[54] R. L. Batterham, M. A. Cowley, C. J. Small et al., "Gut hormone PYY3-36 physiologically inhibits food intake," Nature, vol. 418, no. 6898, pp. 650-654, 2002.

[55] B. Zahorska-Markiewicz, K. Mizia-Stec, M. OlszaneckaGlinianowicz, and J. Janowska, "Effect of weight reduction on serum ghrelin and TNF $\alpha$ concentrations in obese women," European Journal of Internal Medicine, vol. 15, no. 3, pp. 172175, 2004.

[56] M. Olszanecka-Glinianowicz, B. Zahorska-Markiewicz, P. Kocełak, J. Janowska, M. Holecki, and E. Semik-Grabarczyk, 
"The effect of weight loss treatment using Orlistat on serum concentrations of ghrelin and peptide YY," International Journal of Obesity, vol. 31, supplement 1, article 80, 2007.

[57] M. Olszanecka-Glinianowicz, P. Kocełak, T. Wikarek et al., "Are plasma ghrelin and PYY concentrations associated with obesity-related depression?” Endokrynologia Polska, vol. 61, no. 2, pp. 174-177, 2010.

[58] J. Istvan, K. Zavela, and G. Weidner, "Body weight and psychological distress in NHANES I," International Journal of Obesity, vol. 16, no. 12, pp. 999-1003, 1992.

[59] K. M. Carpenter, D. S. Hasin, D. B. Allison, and M. S. Faith, "Relationships between obesity and DSM-IV major depressive disorder, suicide ideation, and suicide attempts: results from a general population study," American Journal of Public Health, vol. 90, no. 2, pp. 251-257, 2000.

[60] American Psychiatric Association, Diagnostic and Statistical Manual of Mental Disorders, American Psychiatric Association, Washington, DC, USA, 4th edition, 1994.

[61] S. J. Goldsmith, K. Anger-Friedfeld, S. Beren, D. Rudolph, M. Boeck, and L. Aronne, "Psychiatric illness in patients presenting for obesity treatment," International Journal of Eating Disorders, vol. 12, no. 1, pp. 63-71, 1992.

[62] K. A. Halmi, M. Long, A. J. Stunkard, and E. Mason, "Psychiatric diagnosis of morbidly obese gastric bypass patients," American Journal of Psychiatry, vol. 134, no. 4, pp. 470-472, 1980.

[63] T. A. Wadden, D. B. Sarwer, L. G. Womble, G. D. Foster, B. G. McGuckin, and A. Schimmel, "Psychosocial aspects of obesity and obesity surgery," Surgical Clinics of North America, vol. 81, no. 5, pp. 1001-1024, 2001.

[64] M. Olszanecka-Glinianowicz, B. Zahorska-Markiewicz, P. Kocełak et al., "Depression in obese persons before starting complex group weight-reduction programme," International Journal of Social Psychiatry, vol. 55, no. 5, pp. 407-413, 2009.

[65] A. J. Stunkard, "Binge eating and the night eating disorder," in Handbook of Obesity Treatment, T. A. Wadden and A. J. Stunkard, Eds., pp. 107-121, Guilford Press, New York, NY, USA, 2002.

[66] M. R. Hebl and L. M. Mannix, "The weight of obesity in evaluating others: a mere proximity effect," Personality and Social Psychology Bulletin, vol. 29, no. 1, pp. 28-38, 2003.

[67] J. Rodin, "Determinants of body fat localization and its implications for health," Annals of Behavioral Medicine, vol. 14, no. 4, pp. 275-281, 1992.

[68] K. M. Flegal, M. D. Carroll, C. L. Ogden, and C. L. Johnson, "Prevalence and trends in obesity among US adults, 19992000," Journal of the American Medical Association, vol. 288, no. 14, pp. 1723-1727, 2002.

[69] M. A. Friedman and K. D. Brownell, "Psychological correlates of obesity: moving to the next research generation," Psychological Bulletin, vol. 117, no. 1, pp. 3-20, 1995.

[70] J. S. M. Lidstone, L. J. Ells, P. Finn, V. J. Whittaker, J. R. Wilkinson, and C. D. Summerbell, "Independent associations between weight status and disability in adults: results from the health survey for England," Public Health, vol. 120, no. 5, pp. 412-417, 2006.

[71] G. Zhao, E. S. Ford, S. Dhingra, C. Li, T. W. Strine, and A. H. Mokdad, "Depression and anxiety among US adults: associations with body mass index," International Journal of Obesity, vol. 33, no. 2, pp. 257-266, 2009.

[72] R. E. Roberts, S. Deleger, W. J. Strawbridge, and G. A. Kaplan, "Prospective association between obesity and depression: evidence from the Alameda County study," International Journal of Obesity, vol. 27, no. 4, pp. 514-521, 2003.
[73] E. Goodman and R. C. Whitaker, "A prospective study of the role of depression in the development and persistence of adolescent obesity," Pediatrics, vol. 110, no. 3, pp. 497-504, 2002.

[74] L. P. Richardson, R. Davis, R. Poulton et al., "A longitudinal evaluation of adolescent depression and adult obesity," Archives of Pediatrics and Adolescent Medicine, vol. 157, no. 8, pp. 739-745, 2003.

[75] A. J. Stunkard, M. S. Faith, and K. C. Allison, "Depression and obesity," Biological Psychiatry, vol. 54, no. 3, pp. 330-337, 2003.

[76] B. Blaine, "Does depression cause obesity?: a meta-analysis of longitudinal studies of depression and weight control," Journal of Health Psychology, vol. 13, no. 8, pp. 1190-1197, 2008.

[77] B. Ludescher, A. Najib, S. Baar et al., "Increase of visceral fat and adrenal gland volume in women with depression: preliminary results of a morphometric MRI study," International Journal of Psychiatry in Medicine, vol. 38, no. 3, pp. 229-240, 2008.

[78] P. Björntorp, "Do stress reactions cause abdominal obesity and comorbidities?" Obesity Reviews, vol. 2, no. 2, pp. 73-86, 2001.

[79] G. Zhao, E.S. Ford, C. Li, J. Tsai, S. Dhingra, and L. S. Balluz, "Waist circumference, abdominal obesity, and depression among overweight and obese U.S. adults: national health and nutrition examination survey 2005-2006," BMC Psychiatry, vol. 11, article 130, 2011.

[80] H. Koponen, J. Jokelainen, S. Keinänen-Kiukaanniemi, E. Kumpusalo, and M. Vanhala, "Metabolic syndrome predisposes to depressive symptoms: a population-based 7-year follow-up study," Journal of Clinical Psychiatry, vol. 69, no. 2, pp. 178-182, 2008.

[81] S. C. Bischoff, A. Damms-Machado, C. Betz et al., "Multicenter evaluation of an interdisciplinary 52-week weight loss program for obesity with regard to body weight, comorbidities and quality of life- a prospective study," International Journal of Obesity, vol. 36, pp. 614-624, 2012.

[82] B. E. Blaine, J. Rodman, and J. M. Newman, "Weight loss treatment and psychological well-being: a review and metaanalysis," Journal of Health Psychology, vol. 12, no. 1, pp. 6682, 2007.

[83] A. L. Palmeira, P. J. Teixeira, T. L. Branco et al., "Predicting short-term weight loss using four leading health behavior change theories," International Journal of Behavioral Nutrition and Physical Activity, vol. 4, article 14, 2007.

[84] C. H. Wu, H. C. Kuo, C. S. Chang, and L. Yu, "What extent of weight loss can benefit the health-related quality of life in motivated obese Chinese?" Asia Pacific Journal of Clinical Nutrition, vol. 18, no. 3, pp. 423-432, 2009.

[85] H. J. Pan, B. M. Cole, and A. Geliebter, "The benefits of body weight loss on health-related quality of life," Journal of the Chinese Medical Association, vol. 74, no. 4, pp. 169-175, 2011.

[86] National Heart, Lung, and Blood Institute, "The practical guide to the identification, evaluation and treatment of overweight and obesity in adults," Tech. Rep. 00-4084, National Institutes of Health, Bethesda, Md, USA, 2000.

[87] A. N. Fabricatore and T. A. Wadden, "Psychological aspects of obesity," Clinics in Dermatology, vol. 22, no. 4, pp. 332-337, 2004.

[88] D. L. Chambless, "Training and dissemination of empirically validated psychological treatments: report and recommendations," Clinical Psychology Review, vol. 48, pp. 3-23, 1995. 
[89] S. M. Sampson, "Treating depression with selective serotonin reuptake inhibitors: a practical approach," Mayo Clinic Proceedings, vol. 76, no. 7, pp. 739-744, 2001.

[90] E. Rieger, S. W. Touyz, and P. J. V. Beumont, "Medical and psychiatric morbidity in obese women with and without binge eating," International Journal of Eating Disorders, vol. 32, no. 1, pp. 72-78, 2002.

[91] T. V. Van Strien, R. C. M. E. Engels, J. V. Leeuwe, and H. M. Snoek, "The Stice model of overeating: tests in clinical and non-clinical samples," Appetite, vol. 45, no. 3, pp. 205-213, 2005.

[92] A. A. Deeks, M. E. Gibson-Helm, E. Paul, and H. J. Teede, "Is having polycystic ovary syndrome a predictor of poor psychological function including anxiety and depression?" Human Reproduction, vol. 26, no. 6, pp. 1399-1407, 2011.

[93] N. Sonino, G. A. Fava, E. Mani, P. Belluardo, and M. Boscaro, "Quality of life of hirsute women," Postgraduate Medical Journal, vol. 69, no. 809, pp. 186-189, 1993.

[94] S. Elsenbruch, S. Benson, S. Hahn et al., "Determinants of emotional distress in women with polycystic ovary syndrome," Human Reproduction, vol. 21, no. 4, pp. 1092-1099, 2006.

[95] N. L. Rasgon, R. C. Rao, S. Hwang et al., "Depression in women with polycystic ovary syndrome: clinical and biochemical correlates," Journal of Affective Disorders, vol. 74, no. 3, pp. 299-304, 2003.

[96] L. Barnard, D. Ferriday, N. Guenther, B. Strauss, A. H. Balen, and L. Dye, "Quality of life and psychological well being in polycystic ovary syndrome," Human Reproduction, vol. 22, no. 8, pp. 2279-2286, 2007.

[97] J. D. Paulson, B. S. Haarmann, R. L. Salerno, and P. Asmar, "An investigation of the relationship between emotional maladjustment and infertility," Fertility and Sterility, vol. 49, no. 2, pp. 258-262, 1988.

[98] J. G. McCook, N. E. Reame, and S. S. Thatcher, "Healthrelated quality of life issues in women with polycystic ovary syndrome," Journal of Obstetric, Gynecologic, and Neonatal Nursing, vol. 34, no. 1, pp. 12-20, 2005.

[99] J. Daniels, "Weight and weight concerns: are they associated with reported depressive symptoms in adolescents?" Journal of Pediatric Health Care, vol. 19, no. 1, pp. 33-41, 2005.

[100] D. Neumark-Sztainer, M. Story, P. J. Hannan, C. L. Perry, and L. M. Irving, "Weight-related concerns and behaviors among overweight and nonoverweight adolescents: implications for preventing weight-related disorders," Archives of Pediatrics and Adolescent Medicine, vol. 156, no. 2, pp. 171-178, 2002.

[101] S. L. Hedden, S. Davidson, and C. B. Smith, "Cause and effect: the relationship between acne and self-esteem in the adolescent years," Journal for Nurse Practitioners, vol. 4, no. 8, pp. 595-600, 2008.

[102] C. Kitzinger and J. Willmott, "'The thief of womanhood': women's experience of polycystic ovarian syndrome," Social Science and Medicine, vol. 54, no. 3, pp. 349-361, 2002.

[103] E. S. Sills, M. Perloe, M. J. Tucker, C. R. Kaplan, M. G. Genton, and G. L. Schattman, "Diagnostic and treatment characteristics of polycystic ovary syndrome: descriptive measurements of patient perception and awareness from 657 confidential self-reports," BMC Women's Health, vol. 1, article 3, 2001.

[104] C. L. Weiner, M. Primeau, and D. A. Ehrmann, "Androgens and mood dysfunction in women: comparison of women with polycystic ovarian syndrome to healthy controls," Psychosomatic Medicine, vol. 66, no. 3, pp. 356-362, 2004.
[105] M. Månsson, J. Holte, K. Landin-Wilhelmsen, E. Dahlgren, A. Johansson, and M. Landén, "Women with polycystic ovary syndrome are often depressed or anxious-a case control study," Psychoneuroendocrinology, vol. 33, no. 8, pp. 11321138, 2008

[106] W. Bruce-Jones, G. Zolese, and P. White, "Polycystic ovary syndrome and psychiatric morbidity," Journal of Psychosomatic Obstetrics and Gynaecology, vol. 14, no. 2, pp. 111-116, 1993.

[107] S. B. Patten and C. J. Lamarre, "Can drug-induced depressions by identified by their clinical features?" Canadian Journal of Psychiatry, vol. 37, no. 3, pp. 213-215, 1992.

[108] E. W. Freeman, K. Rickels, J. Tausig, A. Boxer, L. Mastroianni, and R. W. Tureck, "Emotional and psychosocial factors in follow-up of women after ivf-et treatment. A pilot investigation," Acta Obstetricia et Gynecologica Scandinavica, vol. 66, no. 6, pp. 517-521, 1987.

[109] P. P. Mahlstedt, S. Macduff, and J. Bernstein, "Emotional factors and the in vitro fertilization and embryo transfer process," Journal of In Vitro Fertilization and Embryo Transfer, vol. 4, no. 4, pp. 232-236, 1987.

[110] J. Wright, C. Duchesne, S. Sabourin, F. Bissonnette, J. Benoit, and Y. Girard, "Psychosocial distress and infertility: men and women respond differently," Fertility and Sterility, vol. 55, no. 1, pp. 100-108, 1991.

[111] A. D. Domar, A. Broome, P. C. Zuttermeister, M. Seibel, and R. Friedman, "The prevalence and predictability of depression in infertile women," Fertility and Sterility, vol. 58, no. 6, pp. 1158-1163, 1992.

[112] K. Demyttenaere, L. Bonte, M. Gheldof et al., "Coping style and depression level influence outcome in in vitro fertilization," Fertility and Sterility, vol. 69, no. 6, pp. 10261033, 1998.

[113] I. Tarlatzis, B. C. Tarlatzis, I. Diakogiannis et al., "Psychosocial impacts of infertility on Greek couples," Human Reproduction, vol. 8, no. 3, pp. 396-401, 1993.

[114] K. E. Williams and L. N. Zappert, "Psychopathology and psychopharmacology in the infertile patient," in Infertility Counselling, S. N. Covington and L. H. Burns, Eds., pp. 97116, Cambridge University Press, New York, NY, USA, 2006.

[115] K. M. Anderson, M. Sharpe, A. Rattray, and D. S. Irvine, "Distress and concerns in couples referred to a specialist infertility clinic," Journal of Psychosomatic Research, vol. 54, no. 4, pp. 353-355, 2003.

[116] I. H. Lok, D. T. S. Lee, L. P. Cheung, W. S. Chung, W. K. Lo, and C. J. Haines, "Psychiatric morbidity amongst infertile Chinese women undergoing treatment with assisted reproductive technology and the impact of treatment failure," Gynecologic and Obstetric Investigation, vol. 53, no. 4, pp. 195-199, 2002.

[117] C. R. Newton, M. T. Hearn, and A. A. Yuzpe, "Psychological assessment and follow-up after in vitro fertilization: assessing the impact of failure," Fertility and Sterility, vol. 54, no. 5, pp. 879-886, 1990.

[118] F. Chiaffarino, M. P. Baldini, C. Scarduelli et al., "Prevalence and incidence of depressive and anxious symptoms in couples undergoing assisted reproductive treatment in an Italian infertility department," European Journal of Obstetrics Gynecology and Reproductive Biology, vol. 158, pp. 235-241, 2011.

[119] A. B. Makanjuola, A. O. Elegbede, and O. A. Abiodun, "Predictive factors for psychiatric morbidity among women with infertility attending a gynaecology clinic in Nigeria," African Journal of Psychiatry, vol. 13, no. 1, pp. 36-42, 2010. 
[120] C. A. McMahon, J. A. Ungerer, J. Beaurepaire, C. Tennant, and D. Saunders, "Anxiety during pregnancy and fetal attachment after in-vitro fertilization conception," Human Reproduction, vol. 12, no. 1, pp. 176-182, 1997.

[121] K. Bisaga, E. Petkova, J. Cheng, M. Davies, J. F. Feldman, and A. H. Whitaker, "Menstrual functioning and psychopathology in a county-wide population of high school girls," Journal of the American Academy of Child and Adolescent Psychiatry, vol. 41, no. 10, pp. 1197-1204, 2002.

[122] M. D. Marcus, T. L. Loucks, and S. L. Berga, "Psychological correlates of functional hypothalamic amenorrhea," Fertility and Sterility, vol. 76, no. 2, pp. 310-316, 2001.

[123] A. Calzeroni, G. Conte, A. Pennati, A. Vita, and E. Sacchetti, "Celibacy and fertility rates in patients with major affective disorders: the relevance of delusional symptoms and suicidal behaviour," Acta Psychiatrica Scandinavica, vol. 82, no. 4, pp. 309-310, 1990.

[124] B. L. Harlow, L. A. Wise, M. W. Otto, C. N. Soares, and L. S. Cohen, "Depression and its influence on reproductive endocrine and menstrual cycle markers associated with perimenopause: the Harvard study of moods and cycles," Archives of General Psychiatry, vol. 60, no. 1, pp. 29-36, 2003.

[125] N. L. Rasgon, L. L. Altshuler, D. Gudeman et al., "Medication status and polycystic ovary syndrome in women with bipolar disorder: a preliminary report," Journal of Clinical Psychiatry, vol. 61, no. 3, pp. 173-178, 2000.

[126] K. E. Williams, W. K. Marsh, and N. I. Rasgon, "Mood disorders and fertility in women: a critical review of the literature and implications for future research," Human Reproduction Update, vol. 13, no. 6, pp. 607-616, 2007.

[127] A. A. Noorbala, F. Ramezanzadeh, N. Abedinia, and M. M. Naghizadeh, "Psychiatric disorders among infertile and fertile women," Social Psychiatry and Psychiatric Epidemiology, vol. 44, no. 7, pp. 587-591, 2009.

[128] A. A. Noorbala, K. Mohammad, and S. A. Yazdi, "Prevalence of psychiatric disorders in Tehran (Iran)," Hakim Journal, vol. 2, pp. 214-223, 1999.

[129] T. Wischmann, H. Stammer, H. Scherg, I. Gerhard, and R. Verres, "Psychosocial characteristics of infertile couples: a study by the "Heidelberg fertility consultation service," Human Reproduction, vol. 16, no. 8, pp. 1753-1761, 2001.

[130] J. Boivin, "A review of psychosocial interventions in infertility," Social Science and Medicine, vol. 57, no. 12, pp. 23252341, 2003.

[131] N. W. Karjane, D. W. Stovall, N. G. Berger, and D. S. Svikis, "Alcohol abuse risk factors and psychiatric disorders in pregnant women with a history of infertility," Journal of Women's Health, vol. 17, no. 10, pp. 1623-1627, 2008.

[132] M. J. Himelein and S. S. Thatcher, "Depression and body image among women with polycystic ovary syndrome," Journal of Health Psychology, vol. 11, no. 4, pp. 613-625, 2006.

[133] S. Elsenbruch, S. Hahn, D. Kowalsky et al., "Quality of life, psychosocial well-being, and sexual satisfaction in women with polycystic ovary syndrome," Journal of Clinical Endocrinology and Metabolism, vol. 88, no. 12, pp. 58015807, 2003.

[134] E. Stice, C. Hayward, R. P. Cameron, J. D. Killen, and C. B. Taylor, "Body-image and eating disturbances predict onset of depression among female adolescents: a longitudinal study," Journal of Abnormal Psychology, vol. 109, no. 3, pp. 438-444, 2000.

[135] F. J. Raphael, D. A. Rodin, A. Peattie et al., "Ovarian morphology and insulin sensitivity in women with bulimia nervosa," Clinical Endocrinology, vol. 43, no. 4, pp. 451-455, 1995.
[136] R. Azziz, K. S. Woods, R. Reyna, T. J. Key, E. S. Knochenhauer, and B. O. Yildiz, "The prevalence and features of the polycystic ovary syndrome in an unselected population," Journal of Clinical Endocrinology and Metabolism, vol. 89, no. 6, pp. 2745-2749, 2004.

[137] D. Merari, D. Feldberg, A. Elizur, J. Goldman, and B. Modan, "Psychological and hormonal changes in the course of in vitro fertilization," Journal of Assisted Reproduction and Genetics, vol. 9, no. 2, pp. 161-169, 1992.

[138] S. A. Yazdi, J. Bolhari, and D. Shahmohammadi, "Psychiatric disorders in the rural district of Meybod (Yazd, Iran)," Andisheh Va Raftar, vol. 1, article 94, 1994.

[139] C. Lamas, J. Chambry, I. Nicolas, R. Frydman, P. Jeammet, and M. Corcos, "Alexithymia in infertile women," Journal of Psychosomatic Obstetrics and Gynecology, vol. 27, no. 1, pp. 23-30, 2006.

[140] W. Rief, J. Heuser, and M. M. Fichter, "What does the Toronto alexithymia scale TAS-R measure?" Journal of Clinical Psychology, vol. 52, no. 4, pp. 423-429, 1996.

[141] F. Corica, A. Corsonello, G. Apolone et al., "Metabolic syndrome, psychological status and quality of life in obesity: the QUOVADIS study," International Journal of Obesity, vol. 32, no. 1, pp. 185-191, 2008.

[142] E. Mannucci, M. L. Petroni, N. Villanova, C. M. Rotella, G. Apolone, and G. Marchesini, "Clinical and psychological correlates of health-related quality of life in obese patients," Health and Quality of Life Outcomes, vol. 8, article no. 90, 2010.

[143] E. López-García, J. R. Banegas Banegas, J. L. GutiérrezFisac, A. Gzaciani Pérez-Regadera, L. Díez- Gañán, and F. Rodríguez-Artalejo, "Relation between body weight and health-related quality of life among the elderly in Spain," International Journal of Obesity, vol. 27, no. 6, pp. 701-709, 2003.

[144] P. Zaninotto, M. Pierce, E. Breeze, C. D. Oliveira, and M. Kumari, "BMI and waist circumference as predictors of wellbeing in older adults: findings from the English longitudinal study of ageing," Obesity, vol. 18, no. 10, pp. 1981-1987, 2010 .

[145] D. L. Zabelina, A. L. Erickson, R. L. Kolotkin, and R. D. Crosby, "The effect of age on weight-related quality of life in overweight and obese individuals," Obesity, vol. 17, no. 7, pp. 1410-1413, 2009.

[146] A. Myers and J. C. Rosen, "Obesity stigmatization and coping: relation to mental health symptoms, body image, and self-esteem," International Journal of Obesity, vol. 23, no. 3, pp. 221-230, 1999.

[147] B. Adolfsson, S. Elofsson, S. Rössner, and A. L. Undén, “Are sexual dissatisfaction and sexual abuse associated with obesity? A population-based study," Obesity Research, vol. 12, no. 10, pp. 1702-1709, 2004.

[148] I. Melin, C. Falconer, S. Rössner, and D. Altman, "Sexual function in obese women: impact of lower urinary tract dysfunction," International Journal of Obesity, vol. 32, no. 8, pp. 1312-1318, 2008.

[149] M. P. Mussell, J. E. Mitchell, M. de Zwaan, R. D. Crosby, H. C. Seim, and S. J. Crow, "Clinical characteristics associated with binge eating in obese females: a descriptive study," International Journal of Obesity, vol. 20, no. 4, pp. 324-331, 1996.

[150] G. P. Pimenta, R. T. Saruwatari, M. R. A. Corrêa, P. L. Genaro, and J. E. De Aguilar-Nascimento, "Mortality, weight loss and quality of life of patients with morbid obesity: evaluation of 
the surgical and medical treatment after 2 years," Arquivos de Gastroenterologia, vol. 47, no. 3, pp. 263-269, 2010.

[151] M. Suter, A. Donadini, S. Romy, N. Demartines, and V. Giusti, "Laparoscopic Roux-En-Y gastric bypass: significant long-term weight loss, improvement of obesity-related comorbidities and quality of life," Annals of Surgery, vol. 254, no. 2, pp. 267-273, 2011.

[152] T. J. Loux, R. N. Haricharan, R. H. Clements et al., "Healthrelated quality of life before and after bariatric surgery in adolescents," Journal of Pediatric Surgery, vol. 43, no. 7, pp. 1275-1279, 2008.

[153] M. Helmiö, P. Salminen, H. Sintonen, J. Ovaska, and M. Victorzon, "A 5-year prospective quality of life analysis following laparoscopic adjustable gastric banding for morbid obesity," Obesity Surgery, vol. 21, no. 10, pp. 1585-1591, 2011.

[154] W. J. Clayton, M. Lipton, J. Elford, M. Rustin, and L. Sherr, "A randomized controlled trial of laser treatment among hirsute women with polycystic ovary syndrome," British Journal of Dermatology, vol. 152, no. 5, pp. 986-992, 2005.

[155] A. Drosdzol and V. Skrzypulec, "Quality of life and sexual functioning of Polish infertile couples," European Journal of Contraception and Reproductive Health Care, vol. 13, no. 3, pp. 271-281, 2008.

[156] B. Rashidi, F. Ramezanzadeh, A. Montazeri, M. Shariat, N. Abedinia, and M. Ashrafi, "Health-related quality of life in infertile couples receiving IVF or ICSI treatment," BMC Health Services Research, vol. 8, article 186, 2008.

[157] S. Tan, S. Hahn, S. Benson et al., "Psychological implications of infertility in women with polycystic ovary syndrome," Human Reproduction, vol. 23, no. 9, pp. 2064-2071, 2008.

[158] G. L. Jones, M. Palep-Singh, W. L. Ledger et al., "Do South Asian women with PCOS have poorer health-related quality of life than Caucasian women with PCOS? A comparative cross-sectional study," Health and Quality of Life Outcomes, vol. 8, article 149, 2010.

[159] S. Coffey, G. Bano, and H. D. Mason, "Health-related quality of life in women with polycystic ovary syndrome: a comparison with the general population using the Polycystic Ovary Syndrome Questionnaire (PCOSQ) and the Short Form-36 (SF-36)," Gynecological Endocrinology, vol. 22, no. 2, pp. 8086, 2006.

[160] B. Kaneshiro, J. T. Jensen, N. E. Carlson, S. M. Harvey, M. D. Nichols, and A. B. Edelman, "Body mass index and sexual behavior," Obstetrics and Gynecology, vol. 112, no. 3, pp. 586592, 2008.

[161] N. Bajos, K. Wellings, C. Laborde, C. Moreau, and CSF Group, "Sexuality and obesity, a gender perspective: results from French national random probability survey of sexual behaviours," British Medical Journal, vol. 340, Article ID c2573, 2010.

[162] T. D. S. Pol, "Norms and attitudes to body fatness: a European comparison," Population and Societies, vol. 455, pp. 2-4, 2009.

[163] C. N. Martar, S. C. Yap, L. S. Lin, A. A. Agarwal, P. C. Wong, and M. Choolani, "Care of women in menopause: sexual function, dysfunction and therapeutic modalities," Annals of the Academy of Medicine Singapore, vol. 37, no. 3, pp. 215223, 2008.

[164] G. Pace, V. Silvestri, L. Gualá, and C. Vicentini, "Body mass index, urinary incontinence, and female sexual dysfunction: how they affect female postmenopausal health," Menopause, vol. 16, no. 6, pp. 1188-1192, 2009.
[165] R. L. Kolotkin, M. Binks, R. D. Crosby, T. Østbye, R. E. Gress, and T. D. Adams, "Obesity and sexual quality of life," Obesity, vol. 14, no. 3, pp. 472-479, 2006.

[166] S. Hahn, O. E. Janssen, S. Tan et al., "Clinical and psychological correlates of quality-of-life in polycystic ovary syndrome," European Journal of Endocrinology, vol. 153, no. 6, pp. 853860, 2005.

[167] H. M. Conaglen and J. V. Conaglen, "Sexual desire in women presenting for antiandrogen therapy," Journal of Sex and Marital Therapy, vol. 29, no. 4, pp. 255-267, 2003.

[168] A. B. Veras, R. V. Bruno, M. A. P. de Avila, and A. E. Nardi, "Sexual dysfunction in patients with polycystic ovary syndrome: clinical and hormonal correlations," Comprehensive Psychiatry, vol. 52, pp. 486-489, 2010.

[169] M. Trent, S. B. Austin, M. Rich, and C. M. Gordon, "Overweight status of adolescent girls with polycystic ovary syndrome: body mass index as mediator of quality of life," Ambulatory Pediatrics, vol. 5, no. 2, pp. 107-111, 2005.

[170] B. Kaneshiro and B. Kessel, "Obesity and sexuality: is there a connection?” Fem Patient, vol. 34, pp. 38-40, 2009.

[171] M. Fukuda, K. Fukuda, T. Shimizu, W. Yomura, and S. Shimizu, "Kobe earthquake and reduced sperm motility," Human Reproduction, vol. 11, no. 6, pp. 1244-1246, 1996.

[172] B. Zorn, V. Šučur, J. Stare, and H. Meden-Vrtovec, "Decline in sex ratio at birth after 10-day war in Slovenia," Human Reproduction, vol. 17, no. 12, pp. 3173-3177, 2002.

[173] S. Eskiocak, A. S. Gozen, A. S. Kilic, and S. Molla, "Association between mental stress and some antioxidant enzymes of seminal plasma," Indian Journal of Medical Research, vol. 122, no. 6, pp. 491-496, 2005.

[174] L. Fenster, D. F. Katz, A. J. Wyrobek et al., "Effects of psychological stress on human semen quality," Journal of Andrology, vol. 18, no. 2, pp. 194-202, 1997.

[175] C. Olivius, B. Friden, G. Borg, and C. Bergh, "Why do couples discontinue in vitro fertilization treatment? A cohort study," Fertility and Sterility, vol. 81, no. 2, pp. 258-261, 2004.

[176] M. Rajkhowa, A. Mcconnell, and G. E. Thomas, "Reasons for discontinuation of IVF treatment: a questionnaire study," Human Reproduction, vol. 21, no. 2, pp. 358-363, 2006.

[177] R. N. Clarke, S. C. Klock, A. Geoghegan, and D. E. Travassos, "Relationship between psychological stress and semen quality among in-vitro fertilization patients," Human Reproduction, vol. 14, no. 3, pp. 753-758, 1999.

[178] S. Shahid, "Depression in infertile couples," Journal of the College of Physicians and Surgeons Pakistan, vol. 19, no. 6, pp. 395-396, 2009.

[179] V. M. Lopes and M. Leal, "Personality and emotional adjustment in infertility," The Journal of Reproductive Medicine, vol. 57, pp. 153-158, 2012.

[180] J. R. W. Fisher and K. Hammarberg, "Psychological and social aspects of infertility in men: an overview of the evidence and implications for psychologically informed clinical care and future research," Asian Journal of Andrology, vol. 14, no. 1, pp. 121-129, 2012.

[181] A. Drosdzol and V. Skrzypulec, "Depression and anxiety among polish infertile couples-an evaluative prevalence study," Journal of Psychosomatic Obstetrics and Gynecology, vol. 30, no. 1, pp. 11-20, 2009.

[182] B. Zorn, J. Auger, V. Velikonja, M. Kolbezen, and H. MedenVrtovec, "Psychological factors in male partners of infertile couples: relationship with semen quality and early miscarriage," International Journal of Andrology, vol. 31, no. 6, pp. 557-564, 2008. 
[183] N. Gürhan, A. Akyüz, D. Atici, and S. Kisa, "Association of depression and anxiety with oocyte and sperm numbers and pregnancy outcomes during in vitro fertilization treatment," Psychological Reports, vol. 104, no. 3, pp. 796-806, 2009.

[184] M. C. Inhorn, "Middle Eastern masculinities in the age of new reproductive technologies: male infertility and stigma in Egypt and Lebanon," Medical Anthropology Quarterly, vol. 18, no. 2, pp. 162-182, 2004.

[185] H. Volgsten, L. Ekselius, I. S. Poromaa, and A. S. Svanberg, "Personality traits associated with depressive and anxiety disorders in infertile women and men undergoing in vitro fertilization treatment," Acta obstetricia et gynecologica Scandinavica, vol. 89, no. 1, pp. 27-34, 2010.

[186] T. H. Wischmann, "Sexual disorders in infertile couples," Journal of Sexual Medicine, vol. 7, no. 5, pp. 1868-1876, 2010.

[187] R. L. Kolotkin, R. D. Crosby, R. E. Gress, S. C. Hunt, S. G. Engel, and T. D. Adams, "Health and health-related quality of life: differences between men and women who seek gastric bypass surgery," Surgery for Obesity and Related Diseases, vol. 4, no. 5, pp. 651-658, 2008.

[188] A. E. Dingemans, C. Martijn, A. T. M. Jansen, and E. F. van Furth, "The effect of suppressing negative emotions on eating behavior in binge eating disorder," Appetite, vol. 52, no. 1, pp. 51-57, 2009.

[189] M. L. Sulkowski, J. Dempsey, and A. G. Dempsey, "Effects of stress and coping on binge eating in female college students," Eating Behaviors, vol. 12, no. 3, pp. 188-191, 2011.

[190] L. M. Groesz, S. McCoy, J. Carl et al., "What is eating you? Stress and the drive to eat," Appetite, vol. 58, no. 2, pp. 717$721,2012$.

[191] C. G. Greeno, C. Jackson, E. L. Williams, and S. P. Fortmann, "The effect of perceived control over eating on the life satisfaction of women and men: results from a community sample," International Journal of Eating Disorders, vol. 24, no. 4, pp. 415-419, 1998.

[192] C. Akbal, N. Mangir, H. H. Tavukçu, O. Ozgür, and F. Simşek, "Effect of testicular sperm extraction outcome on sexual function in patients with male factor infertility," Urology, vol. 75, no. 3, pp. 598-601, 2010.

[193] R. A. Saleh, G. M. Ranga, R. Raina, D. R. Nelson, and A. Agarwal, "Sexual dysfunction in men undergoing infertility evaluation: a cohort observational study," Fertility and Sterility, vol. 79, no. 4, pp. 909-912, 2003.

[194] R. Conrad, G. Schilling, T. Hagemann, G. Haidl, and R. Liedtke, "Somatization and alexithymia in male infertility. A replication study," Hautarzt, vol. 54, no. 6, pp. 530-535, 2003.

[195] R. Conrad, G. Schilling, M. Langenbuch, G. Haidl, and R. Liedtke, "Alexithymia in male infertility," Human Reproduction, vol. 16, no. 3, pp. 587-592, 2001.

[196] A. Riecher-Rössler, C. Schmid, S. Bleuer, and M. Birkhäuser, "Antipsychotics and hyperpolactinaemia: pathophysiology, clinical relevance, diagnosis and therapy," Neuropsychiatrie, vol. 23, no. 2, pp. 71-83, 2009.

[197] A. C. Svensson, P. Lichtenstein, S. Sandin, and C. M. Hultman, "Fertility of first-degree relatives of patients with schizophrenia: a three generation perspective," Schizophrenia Research, vol. 91, no. 1-3, pp. 238-245, 2007.

[198] C. L. Keating, M. L. Moodie, and B. A. Swinburn, "The health-related quality of life of overweight and obese adolescents a study measuring body mass index and adolescentreported perceptions," International Journal of Pediatric Obesity, vol. 6, no. 5-6, pp. 434-441, 2011.
[199] L. Busetto, V. Pilone, A. M. Schettino et al., "Determinants of health-related quality of life in morbid obese candidates to gastric banding," Eating Weight Disorders. In press.

[200] R. S. Lund, T.-I. Karlsen, D. Hofsø et al., "Employment is associated with the health-related quality of life of morbidly obese persons," Obesity Surgery, vol. 21, no. 11, pp. 17041709, 2011.

[201] M. L. Vetter, T. A. Wadden, J. Lavenberg et al., "Relation of health-related quality of life to metabolic syndrome, obesity, depression and comorbid illnesses," International Journal of Obesity, vol. 35, no. 11, pp. 1087-1094, 2010.

[202] J. L. R. Chachamovich, E. Chachamovich, H. Ezer et al., "Psychological distress as predictor of quality of life in men experiencing infertility: a cross-sectional survey," Reproductive Health, vol. 7, no. 1, article 3, 2010.

[203] J. F. Smith, T. J. Walsh, A. W. Shindel et al., "Sexual, marital, and social impact of a man's perceived infertility diagnosis," Journal of Sexual Medicine, vol. 6, no. 9, pp. 2505-2515, 2009.

[204] J. Chachamovich, E. Chachamovich, M. P. Fleck, F. P. Cordova, D. Knauth, and E. Passos, "Congruence of quality of life among infertile men and women: findings from a couple-based study," Human Reproduction, vol. 24, no. 9, pp. 2151-2157, 2009.

[205] A. W. Shindel, C. J. Nelson, C. K. Naughton, M. Ohebshalom, and J. P. Mulhall, "Sexual function and quality of life in the male partner of infertile couples: prevalence and correlates of dysfunction," Journal of Urology, vol. 179, no. 3, pp. 10561059, 2008.

[206] M. Monga, B. Alexandrescu, S. E. Katz, M. Stein, and T. Ganiats, "Impact of infertility on quality of life, marital adjustment, and sexual function," Urology, vol. 63, no. 1, pp. 126-130, 2004.

[207] J. Elia, M. Delfino, N. Imbrogno, and F. Mazzilli, “The impact of a diagnosis of couple subfertility on male sexual function," Journal of Endocrinological Investigation, vol. 33, no. 2, pp. 74-76, 2010.

[208] L. Reporaki, R. L. Punamaki, L. Unkila-Kallio et al., "Infertility treatment and marital relationships: a 1-year prospective study among successfully treated ART couples and their controls," Human Reproduction, vol. 22, no. 5, pp. 14811491, 2007.

[209] A. Drosdzol and V. Skrzypulec, "Evaluation of marital and sexual interactions of polish infertile couples," Journal of Sexual Medicine, vol. 6, no. 12, pp. 3335-3346, 2009.

[210] K. Jain, G. Radhakrishnan, and P. Agrawal, "Infertility and psychosexual disorders: relationship in infertile couples," Indian Journal of Medical Sciences, vol. 54, no. 1, pp. 1-7, 2000.

[211] M. S. Sand, W. Fisher, R. Rosen, J. Heiman, and I. Eardley, "Erectile dysfunction and constructs of masculinity and quality of life in the multinational Men's Attitudes to Life Events and Sexuality (MALES) study," Journal of Sexual Medicine, vol. 5, no. 3, pp. 583-594, 2008.

[212] B. Cornwell and E. O. Laumann, "Network position and sexual dysfunction: implications of partner betweenness for men," American Journal of Sociology, vol. 117, no. 1, pp. 172208, 2011. 


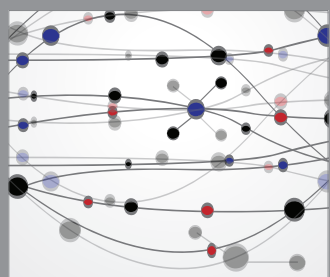

The Scientific World Journal
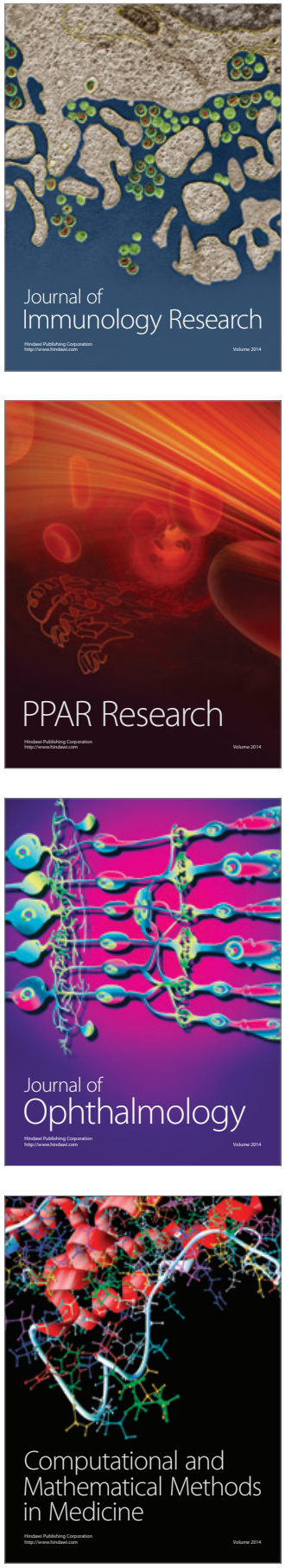

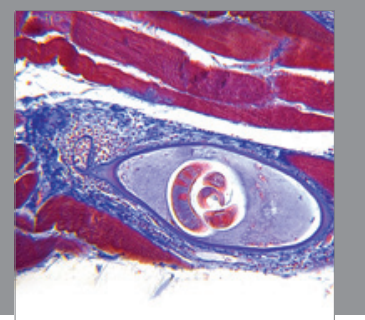

Gastroenterology

Research and Practice
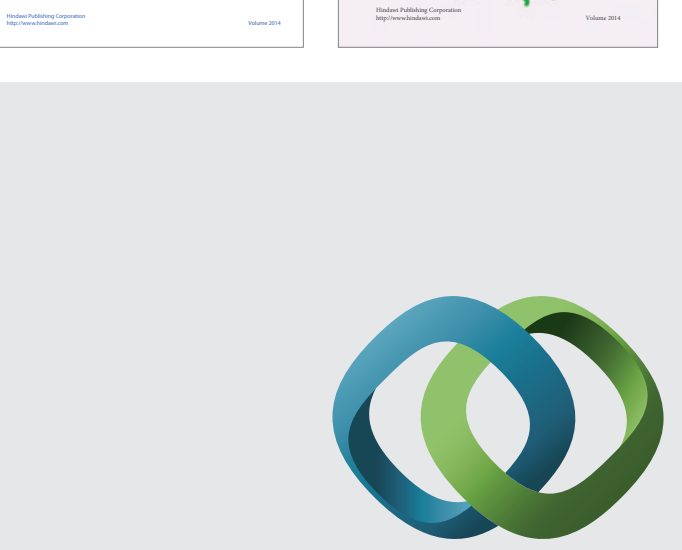

\section{Hindawi}

Submit your manuscripts at

http://www.hindawi.com
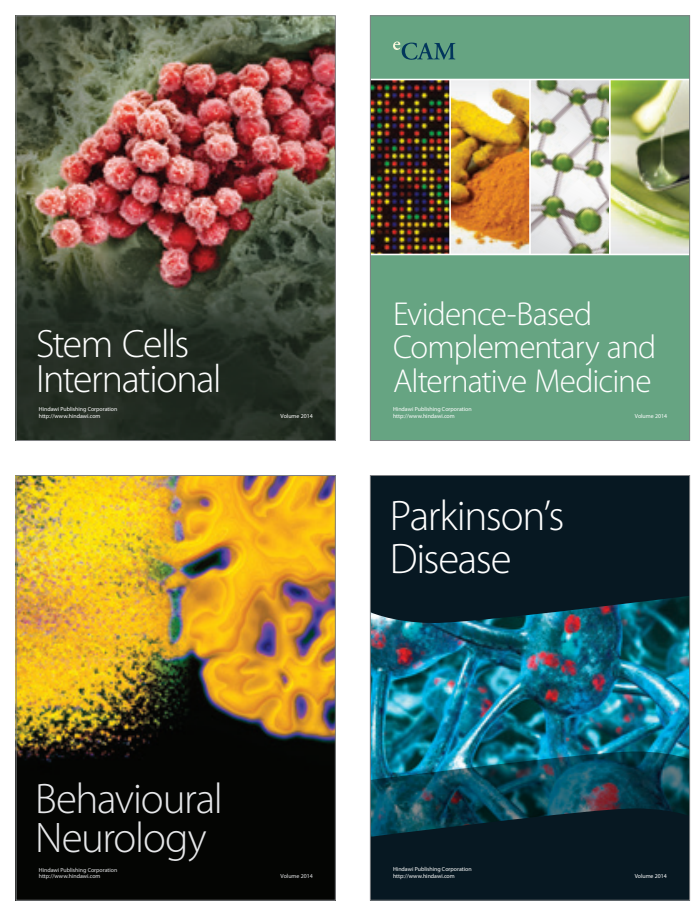

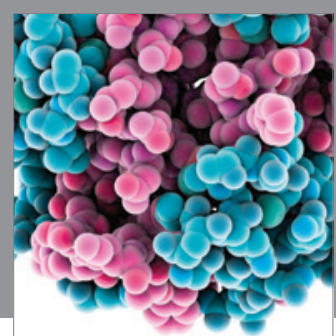

Journal of
Diabetes Research

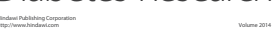

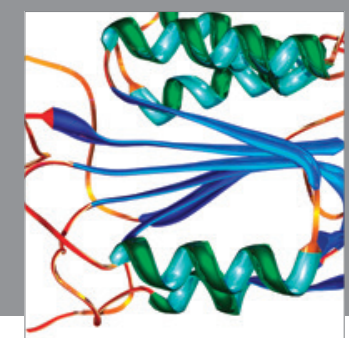

Disease Markers
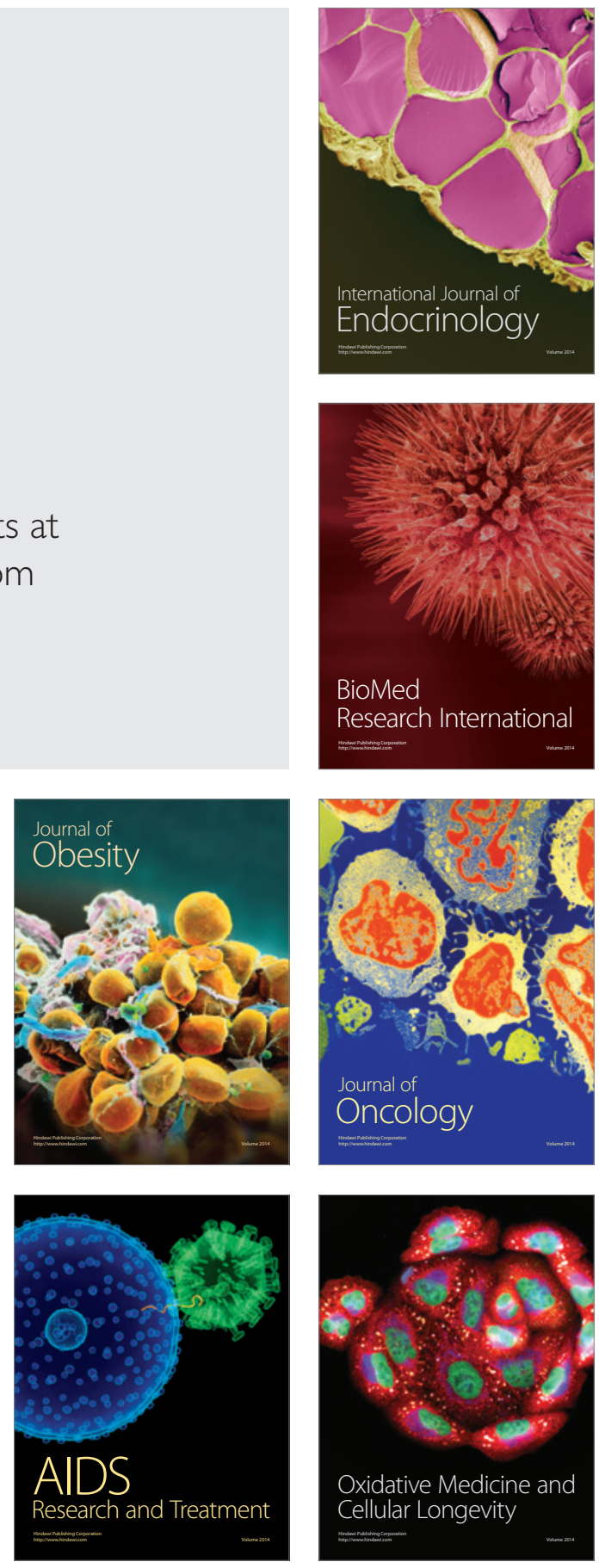